\title{
Anti-Fertility Effect of Allethrin Based Liquid Electric Repellent on the Testes and Epididymis of Adult Male Sprague-Dawley Rat
}

\author{
FALANA Benedict, ADELEKE Opeyemi, ADUNFE Oluwatobi, IDAHOSA Wisdom
}

Department of Anatomy, College of Health Sciences, Osun State University, Osogbo, Nigeria

\begin{abstract}
The incidence of male infertility in a population has important demographic and health implications. Effect of Allethrin on the testes and epididymis is being investigated. The aim of this research work is to determine the effect of allethrin on male reproductive system (testes and epididymis).
\end{abstract}

A total number of twenty (20) adult male Sprague-Dawley rats of mean weight $160 \mathrm{~g}$ were divided into four groups. Group 1, 2 and 3 animals were daily exposed to electric mortein insecticides for 30 minutes, 1 hour and 1 hour 30minutes respectively for 30 days. Group 4 rats were designated as the Control group.

The exposed animals experienced reduction in body weight, significant decrease in numbers of neutrophils, significant increase in white blood cell count and packed cell volume. Andrological parameters showed significant decrease in sperm count, sperm motility, percentage of normal sperm cells and serum testosterone level when compare with the control. Histo-architecture of the testes and epididymis showed seminiferous tubules with incomplete maturation of germinal cell layers with no spermatozoa in their lumen and some epididymal cells were also devoid of sperms. Control rats' testes and epididymis histological parameters appeared normal.

Continuous exposure to inhalation of allethrin causes reduction in body weights. Moreover, this study has revealed its anti-fertility effect on the male reproductive system.

Keywords: Allethrin, Anti-fertility, Testes, Histo-architecture, epididymis

\section{INTRODUCTION}

Pyrethroids are synthetic pesticides chemically related to the naturally occurring pesticide, pyrethrum (Bruce, 2007). Out of thousands of pyrethroids that have been made, only a few are used in the Nigeria. Allethrin is one of the type of pyrethroids that do not have cyano group. It is widely used in Nigeria households to control insects. Its uses in the textiles industry cannot be overlook as it is being used in the making of carpets, wallpapers, furniture and clothes. Allethrin is also being used in agriculture, forestry and public health services. Organism most ingest accidentally via food ingestion or inhalation via polluted air or by skin contact (Macan et al, 2006).

WHO in the year 2001 reported that some agents like chemotherapeutic, radiation, pharmaceutical, pesticides and insecticides have been implicated in the male reproductive dysfunction. These agents act either as direct spermatotoxins or through a steroidal pathway (WHO, 2001). Moreover, histopathological studies of the intoxicated rats treated with methomyl orally $17 \mathrm{mg} / \mathrm{kg}$ in saline daily for two months revealed variable degrees of degenerative changes in the seminiferous tubules up to total cellular destruction (Mahgoub and EI-Medany, 2006). Furthermore, Sobarzo and BustosObregon in the year 2000, reported that a single injection of parathion (an organophosphate agro pesticide) to immature male micecaused a decrease in testis weight and early damage of germ cells of the mice. Quinalphos a commonly used organophosphorus insecticide reduce prostatic acid phosphatase activity and fructose content of the accessory sex glands, and plasma levels of testosterone, FSH, LH as well as relative weights of the testis and accessory sex organs (Rey et al, 1991). Dimethoate orally exposed to male rats increase relative weights of testis and prostate, sperm density and motility, serum and testis levels of protein and cholesterol, activity of prostatic acid phosphatase (Ngoula et al, 2011).

People tend to patronize Pyrethroids based insecticide these days to organophosphate based insecticide due to high intoxication of the latter, and lot of works have been done on anti-fertility 
effects of organophosphate based insecticide but paucity of data as regards to pyrethroids type of insecticide. But how truly saved is pyrethroids based insecticide? Thus this work aims at evaluating the effect of allethrin based liquid electric repellent on the testes and epididymis of adult male Sprague-Dawley rat.

\section{Materials ANd Method}

\subsection{Procurement of Allethrin}

Liquid electric allethrin repellent was procured from commercially available store.

\subsection{Experimental Design}

A total number of twenty (20) adult male Sprague-Dawley rats of mean weight $160 \mathrm{~g}$ were divided into four groups. Group 1, 2 and 3 animals were daily exposed to electric mortein insecticides for 30 minutes, 1 hour and 1 hour 30minutes respectively for 30 days. Group 4 rats were designated as the Control group. The animals were fed with standard rat pellet (Mosodun Ltd.Osogbo, Osun State, Nigeria) with free access to tap water. All the experimental procedures were done following the experimental guidelines of Health Research and Ethics Committee (HREC) of the Osun State University, Osogbo Campus, Osogbo, Osun State.

\subsection{Animal Sacrifice and Sample Collection}

The animals were sacrificed using cervical dislocation, the abdominal regions were excised and testes were removed from the scrotum sac and blotted out of fats before fixing in Boiun's fluid. Blood was collected from the apex of the heart via cardiac puncture.

\subsection{Sperm Count Assay}

Sperm motility was assessed by the method described by (Melissa, 2002). The spermatozoa were counted by hemocytometer using the improved Neubauer (Deep 1/10 mm, LABART, Germany) chamber as described by (Melissa, 2002).

\subsection{Sperm Morphology and Motility Assay}

Sperm live/dead ratio and motility was determined using 1\% Eosin and 5\% Nigrosin in 3\% sodium citrate dehydrate solution according to the method described by (Melissa, 2002).

\subsection{Testosterone Assay}

This was carried out with the use of Testosterone ELISA Kit obtained from Monobind Inc. Lake forest, CA, U.S.A (Product code 3725-300). The essential reagents used for this assay were biotinylated antibody, enzyme-antigen conjugate and a serum native antigen, upon mixing all these reagents, a competitive reaction set-in between the native antigen and enzyme antigen conjugate for a limited number of antibody binding sites. The amount of testosterone that is able to bind to the testosterone antiserum will be inversely proportional to the concentration of testosterone in the well. The absorbance in each well at $450 \mathrm{~nm}$ was read in a microplate reader (using a reference wavelength of $620-630 \mathrm{~nm}$ to minimize well imperfections).

\subsection{Histological Examination}

Routine histological processing using Haematoxylin and Eosin staining method was carried out. The testes were fixed in $10 \%$ formal saline, dehydrated in ascending grades of alcohol, cleared in xylene, quickly dipped into molten paraffin wax before finally embedded in molten paraffin wax in order to form hard block. The hard block containing the tissue was then sectioned by the rotary microtome at $4 \mu \mathrm{m}$ thickness. The sections were then floated in water bath at $40^{\circ} \mathrm{c}$ and transferred to a glass slide and stained with heamatoxylin and eosinstains. The slides were then viewed under light microscope at $\times 100$ and $\times 400$ magnification and photomicrographs were taken in at both magnifications.

\section{Statistical Analysis}

One way ANOVA and student t-test were used to analyse the data using Graph Pad Prism v.6. The results were presented as Mean \pm SEM with significant level at $P$-value $<0.05$ while the histological examination, Sperm analysis and Serum testosterone level were carefully studied and analysed to establish any correlation between the groups. 


\section{ReSults}

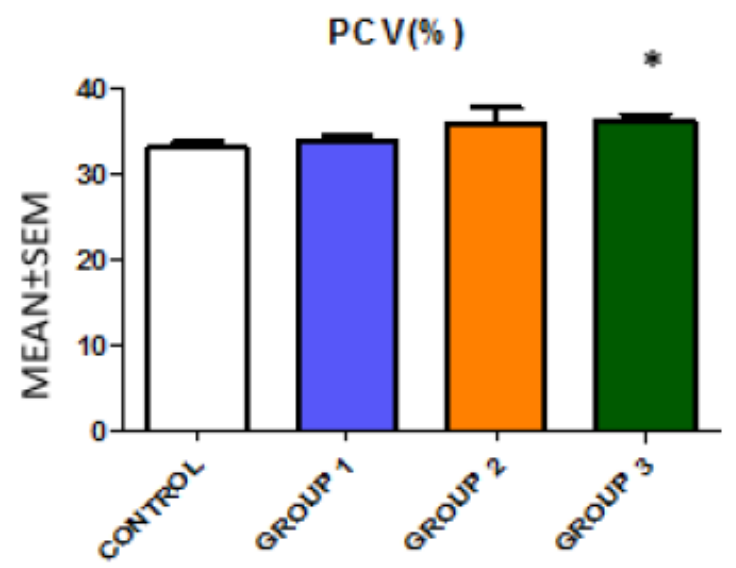

Figure1. Showed comparison between the control group and treated groups packed cell volume after treatment with allethrin. Group 3 rats (1hour 30minutes) showed slight increase in packed cell volume rate $(* P<0.05)$, while group 1 (30 minutes) and group 2 (1 hour) rats showed no significant change statistically.

*: p-value $<\mathbf{0 . 0 5}$

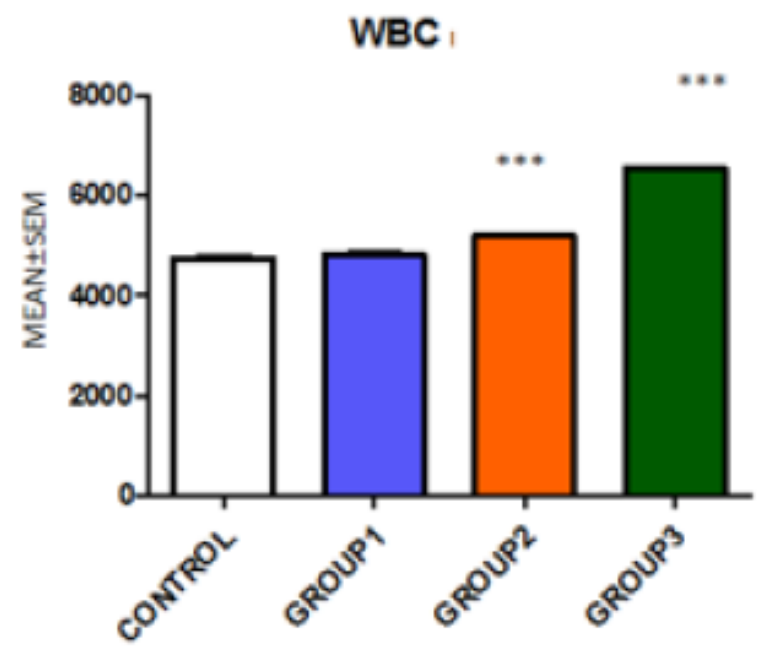

Figure2. Showed comparison between the control and treated groups white blood cell count after treatment with allethrin. Group 2 rats (1hour) and group 3 rats (1hour 30minutes) have high significant increase in white blood cell count $(* * * P<0.0001)$ while group 1 rats $(30$ minutes $)$ showed no significant change statistically.

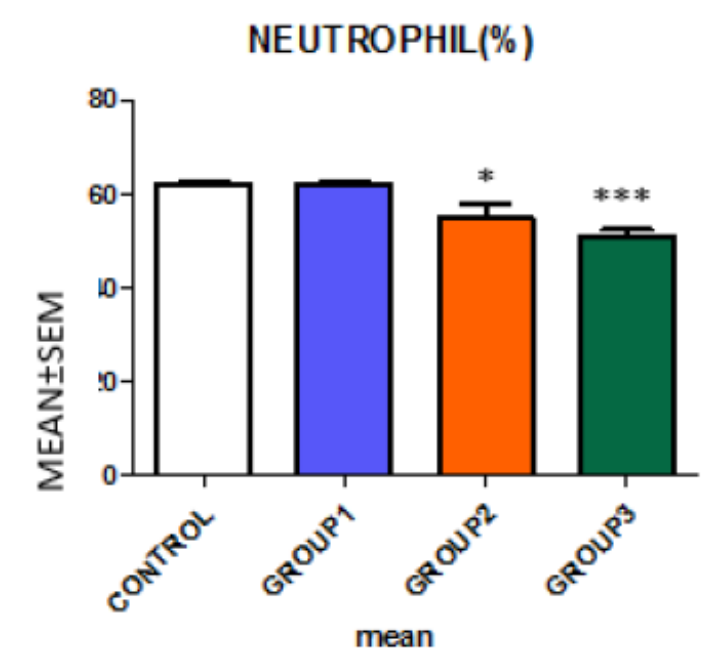

Figure3. Showed comparison between the control group and treated groups number of neutrophils after treatment with allethrin. Group 1 rats (30 minutes) do not show any significant change in their neutrophils, group 2 rats (1 hour) showed slight decrease in their numbers of neutrophils $(* P<0.05)$ while group rats (1hour 30minutes) showed high significant decrease in their number of neutrophils $(* * * P<0.0001)$. 


\section{SERUM TE STO STERONE C ONCENT RATION(ng/ml)}

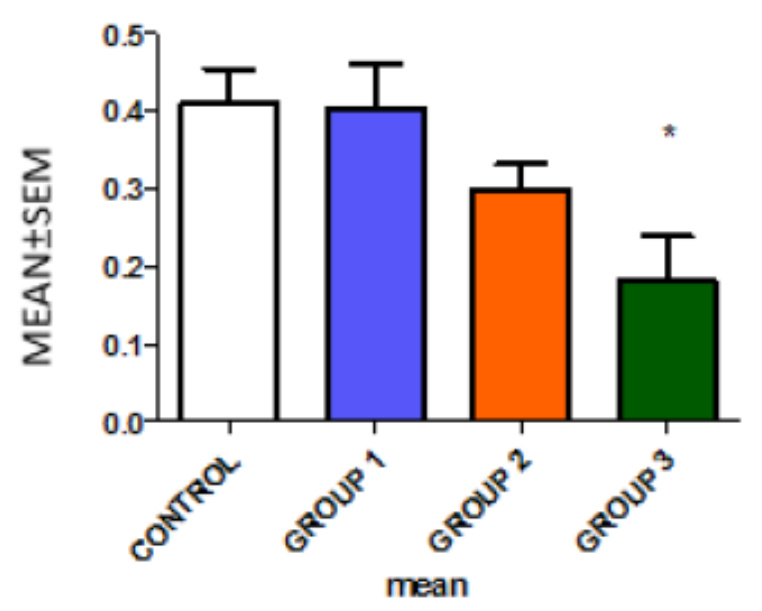

Figure4. Showed comparison between the control group and treated groups serum testosterone after treatment with allethrin. Group 3 rats (1hour 30minutes) showed slight decrease in serum testosterone $(* P<0.05)$

*: $p$ value $<0.05$

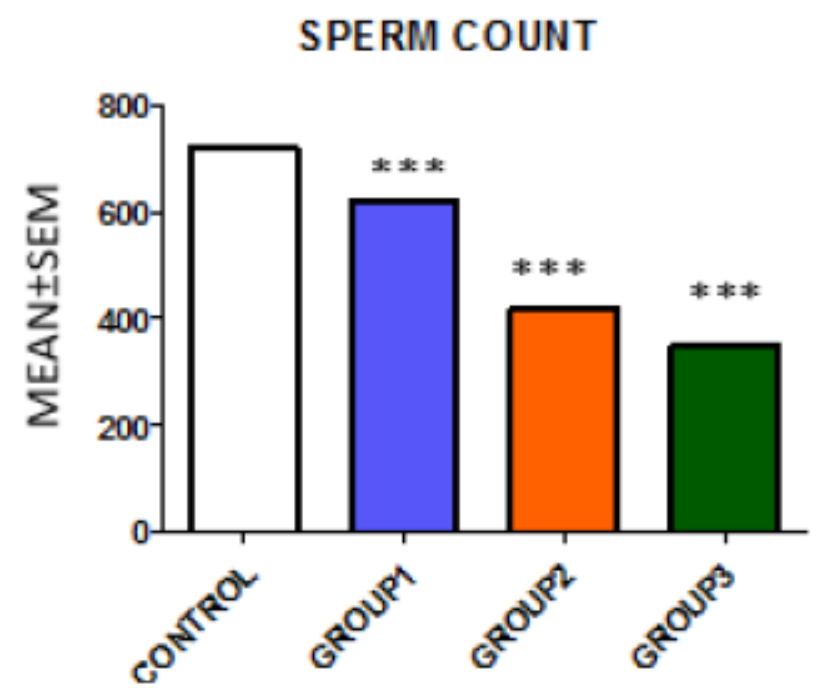

Figure5. Showing reduction across all groups sperm count when compared to the control group $(* * * p<0.0001)$.

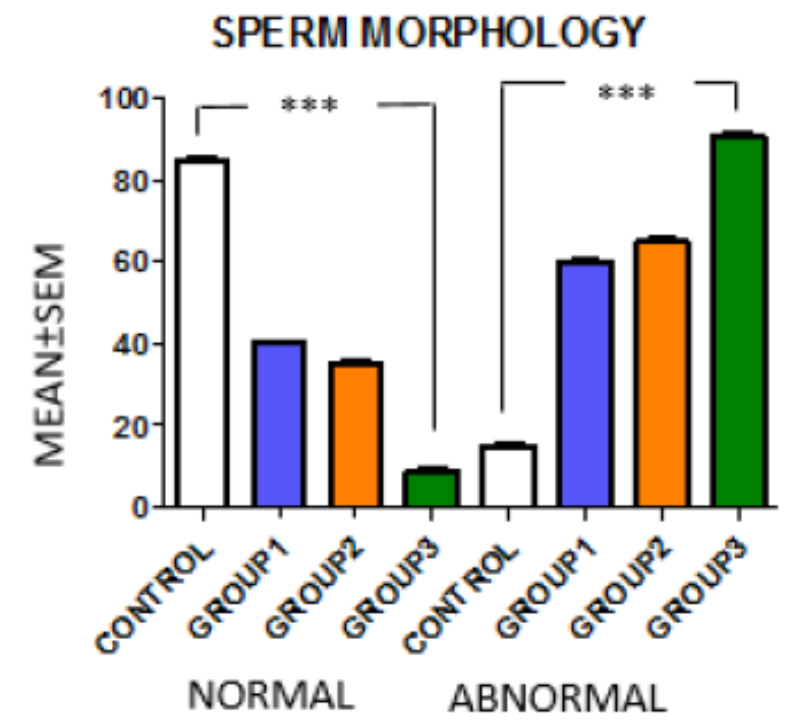

Figure6. showed progressive decrease in amount of normal sperm and progressive increase in number of normal sperm from group 1 to group 3 when comparing with the control group $(* * * p<0.0001)$. 

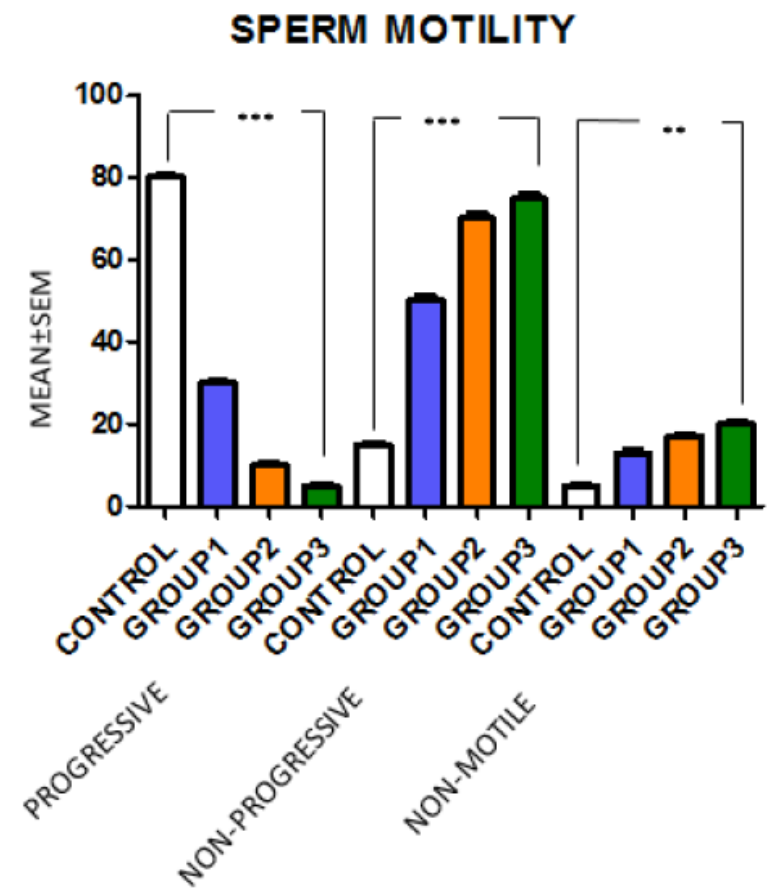

Figure7. showing reduction in sperm motility across all groups from group 1 to group 3 while comparing with the control group $(* * * p<0.0001)$.

\subsection{Photomicrographs}

Figure8.

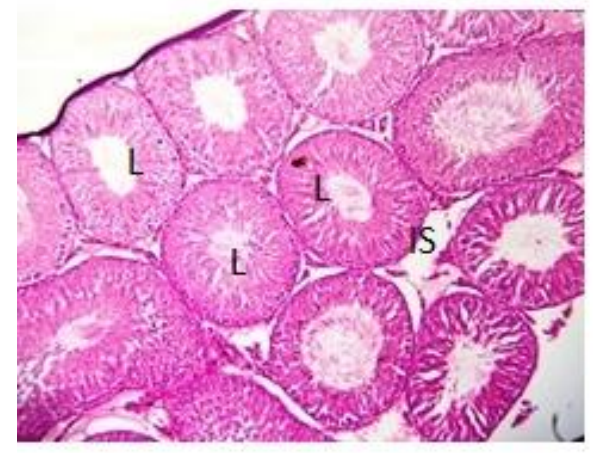

$\times 100$

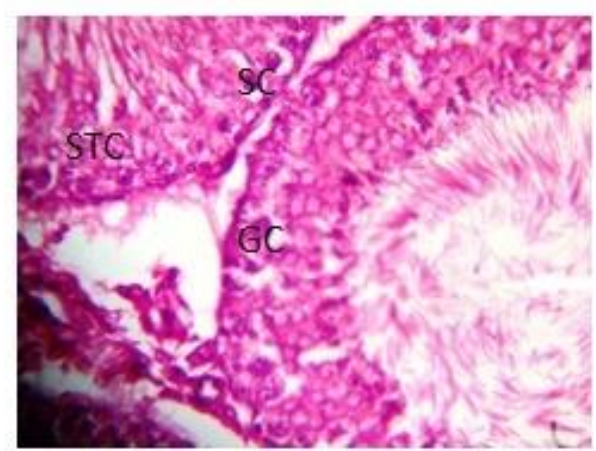

$\times 400$

The longitudinal section of the control group testicular section stained by haematoxylin and eosin showed normal seminiferous tubules with normal spermatogonia cell (SC). Sertoli cells (STC) appeared normal and showed normal germ cell layer (GC) with normal maturation stages, the lumen (L) appear normal with presence of spermatozoa and the interstitial spaces (IS) and Leydig cells (LC) also appeared normal.

Figure9.

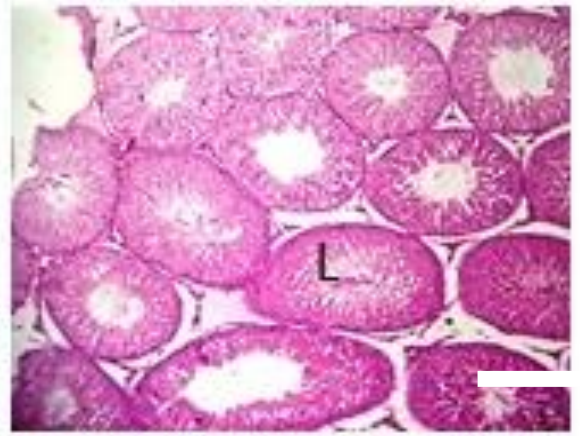

$\mathrm{X} 100$

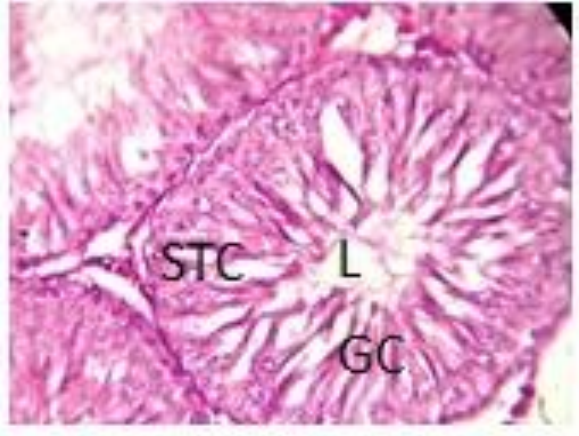

$\times 400$ 
The longitudinal section of group 1 rat testes stained by haematoxylin and eosin showed normal seminiferous tubules with normal spermatogonia cell(SC), normal sertoli cells(STC) and normal germ cell layer (GC) with normal maturation stages, the Lumen (L) appear normal with presence of spermatozoa. Moreover, the interstitial spaces (IS) and leydig cells (LC) appeared normal.

Figure10.
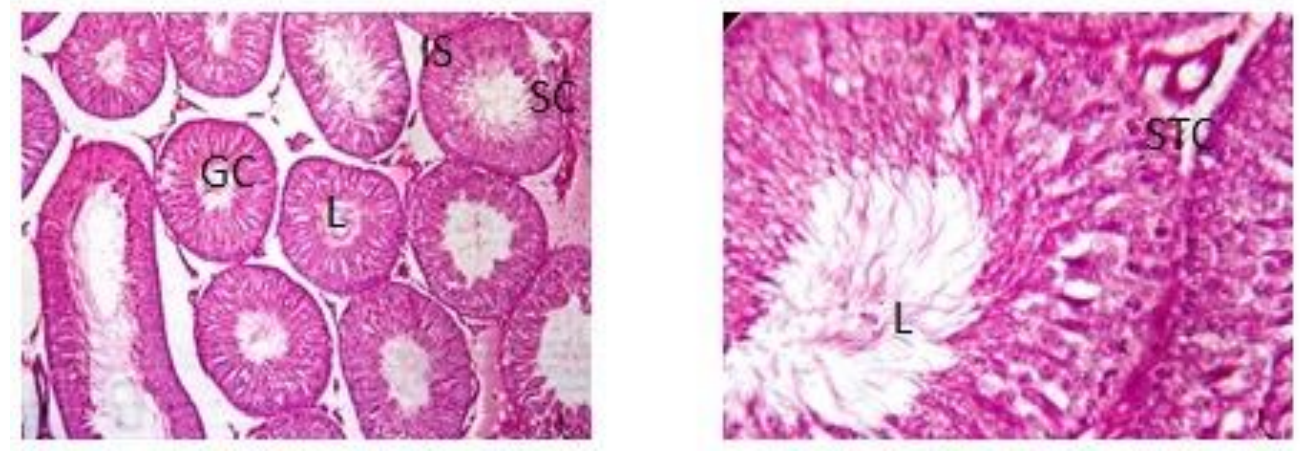

$\times 100$

$\times 400$

The longitudinal section of group 2 testicular section stained by haematoxylin and eosin showed normal seminiferous tubules with normal spermatogonia cell (SC) and normal sertoli cells (STC). Germ cell layer (GC) appeared normal with normal maturation stages, the lumen (L) appear normal with presence of spermatozoa, the interstitial spaces (IS) and leydig cells (LC) appeared normal.

Figure11.

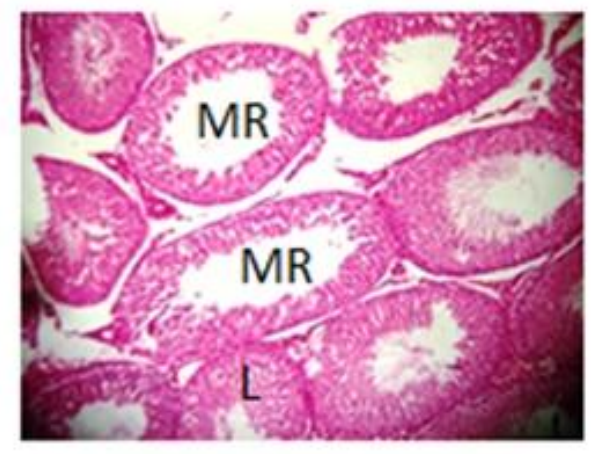

X100

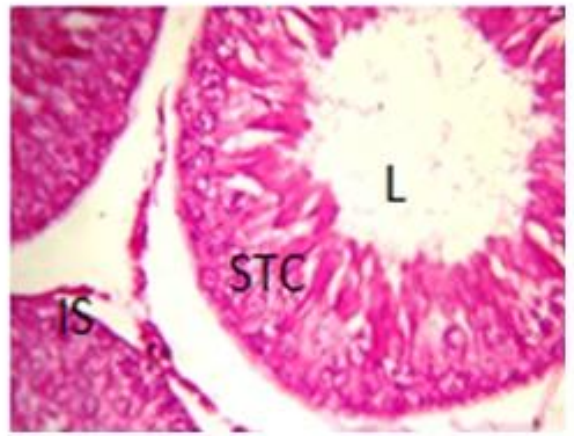

X400

The longitudinal section of group 3 rats testicular section stained by haematoxylin and eosin showed several normal seminiferous tubules with normal spermatogonia cell (SC) and normal sertoli cells (STC). Germinal cell layer (GC) appeared normal with normal maturation stages, the lumen (L) appear normal with presence of spermatozoa. However, there are few seminiferous tubules showing maturation arrest (MR) but the interstitial spaces (IS) and leydig cells (LC) appeared normal.

\section{DISCUSSION AND CONCLUSION}

In this present study, it was observed that exposure to allethrin over a long time as seen across the groups caused significant decrease in body weight and this observation is in agreement with the work of Akunna et al, 2013who discovered that pyrethroid insecticides exposure would cause significant decrease in body weight. The observed body weight loss in this study might be due to reduction in the food consumption and the role of allethrin in pituitary weight loss by degradation which could have led to reduction in growth hormone and hence body weight loss (Fan et al, 2007).

This present study also revealed that exposure to allethrin over a long time as seen most especially in group 3 ( 1 hour 30 minutes) rats caused increase in total white blood cell and packed cell volume counts and this observation is in agreement with the work of Emmanuel et al, 2013 who observed that exposure to pyrethroid insecticides over a long time causes increase in total white blood cell and packed cell volume counts. Increased in these hematological parameters may be due to cyanide which is a bye product of mosquito coil smoke which is known to cause reduction in oxygen carrying capacity of red blood cell leading to reduced metabolism. The reduction of oxygen stimulates erythropoietin which in turn stimulates the bone marrow to produce red blood cells leading to increase packed cell volume (Parker et al, 1984). 
There was marked reduction in serum testosterone concentration for long time allethrin exposed group, this observation is in accord with the work of Meeker et al, 2008 that noticed that exposure to pyrethroid insecticides will cause reduction in serum testosterone concentration.

The seminiferous tubules of the rats exposed over a long time as seen in group 3 rats in this work showed maturation arrest, it was also observed by Shala by et al, 2010 that over exposure to pyrethroid insecticide for a long time induced testicular lesions characterized by moderate to severe degenerative changes of seminiferous tubules and incomplete arrest of spermatogenesis.

In conclusion, over exposure to allethrin has negative effect on male fertility, steps should be taken to avoid individuals from been over exposed to allethrin or pyrethroid insecticides.

\section{REFERENCES}

Bruce Rauner, 2007: Environmental health (Pyrethroid insecticides); Department of Public health, Ilinois

Emmanuel Taiwo Idowu, Oyenmwen Judith Aimufua, Yomi-Onilude Ejovwoke, Bamidele Akinsanya. Olubumi Adetoro Otubanjo., (2013). Toxicological effects of prolonged and intense use of mosquito coil emission in rats and its implications on malaria control. Rev. Biol. Trop. (Int. J. Trop. Biol. ISSN-0034-7744) Vol. 61 (3): 1463-1473.

Fan W, Yanase T, Morinaga H, Gondo S, Okabe T, Nomura M, Komatsu T, Morohashi K, Hayes TB, Takayanagi R and Nawata H., (2007). Atrazine-induced aromatase expression is SF-1 dependent: implications for endocrine disruption in wildlife and reproductive cancers in humans, Environ. Health Perspect., 115 (5), 720-7.

Macan J, Varnai VM, Turk R (2006). Health effects of pyrethrins and pyrethroids, PubMed; 57(2):237-43

Melissa Rouge (2002): Collection and evaluation of semen. Reproductive index Glossary.

Meeker J.D, Barr D.B, Hauser R., (2008). Human semen quality and sperm DNA damage in relation to urinary metabolites of pyrethroid insecticides. Hum reprod;23(8):1932-1940.

Ngoula F, Watcho P, Bouseko T S, Kenfack A, Tchoumboué J, Kamtchouing P., (2007). Effects of propoxur on the reproductive system of male rats. Afr J Reprod Health; 11 (1):125-32.

Pant N and Srivastava SP., (2003). Testicular and spermatotoxic effect of quinaphos in rats. Appl. Toxicol; 23: 271-274.

Parker, C.M., D.R. Patterson and G.A. Van., (1984). Chronic toxicity and carcinogenicity evaluation of fenvalerate in rats. J. Toxicol. Environ. Health 13: 83-97.

Philippov OS, Radionchenko AA, Bolotova VP, Voronovskaya NI, Potemkina T.V., (1998). Estimation of the prevalence and causes of infertility in western Siberia, Bull World Health Organ, 76, 183-87.

Ray A , Chatterjee S, Ghosh S, Kabir SN, Pakrashi A, Deb C., (1991). Suppressive effect of quinalphos on the activity of accessory sex glands and plasma concentrations of gonadotrophins and testosterone in rats. Arch Environ Contam Toxicol.; 21(3):383-387.

Shalaby, M.A, El Zorba, H.Y, Ziada R. M., (2010). Reproductive toxicity of methomyl insecticide in male rats and protective effect of folic acid. Food and Chemical Toxicology; 48: 3221-3226.

Sobarzo C, Bustoos-Obregón E., (2000). Sperm quality in mice acutely treated with parathion. Asian Journal of Andrology a; 2: 147-150.

Sobrazo C, Bustos-Obregon E., (2000). Acute effect of parathion on the seminiferous epithelium of immature mice. Revista Chilena de Anatomia b; 18(1): 6-68.

World Health Organization, (1975) The epidemiology of infertility, Report of W.H.O Scientific Group on the Epidemiology of Infertility, Technical Report Series No. 582, Geneva: World Health Organization.

World Health Organization, (1996). Infertility: A tabulation of available data on prevalence of primary and secondary infertility. Geneva, WHO Programme on Maternal and Child Health and Family Planning, Division of Family Health.

World Health Organization, (2001). Reproductive health indicators for global monitoring: Report of the second interagency meeting, Geneva: World Health Organization. W.H.O/RHR/01.19. 